\title{
Thermal Error Modeling Method for a CNC Machine Tool Feed Drive System
}

\author{
Kuo Liu, ${ }^{1}$ Mingjia Sun, ${ }^{2}$ Yuliang $\mathrm{Wu},{ }^{2}$ and Tiejun $\mathrm{Zhu}^{2}$ \\ ${ }^{1}$ College of Mechanical Engineering, Jilin University, Changchun 130025, China \\ ${ }^{2}$ State Key Laboratory, Shenyang Machine Tool (Group) Co., Ltd., Shenyang 110142, China \\ Correspondence should be addressed to Kuo Liu; liukuo0727@qq.com
}

Received 17 July 2015; Revised 18 September 2015; Accepted 20 September 2015

Academic Editor: Ricardo Aguilar-López

Copyright (c) 2015 Kuo Liu et al. This is an open access article distributed under the Creative Commons Attribution License, which permits unrestricted use, distribution, and reproduction in any medium, provided the original work is properly cited.

\begin{abstract}
The disadvantages of the common current thermal error modeling methods for $\mathrm{CNC}$ machine tool feed drive systems were analyzed, such as the requirement of many temperature sensors to reach high accuracy and poor applicability of different moving states. A new robust modeling method based on the heat transfer theory is proposed, and the procedure of the thermal tests for a feed drive system is presented. Multiple regression method and robust modeling method based on the heat transfer theory were, respectively, used to establish a thermal error model, and a pointer automatic optimizer was used to optimize the parameters in the robust model. A compensation simulation was conducted under five different moving states using these two modeling methods, and the advantages of the robust modeling method were proved. Finally, the compensation effect of the robust modeling method was verified under a random moving state on a vertical machining center.
\end{abstract}

\section{Introduction}

Currently, mainly two methods are used to reduce $\mathrm{CNC}$ machine tool thermal errors: error prevention and error compensation [1]. The error prevention method tries to eliminate or reduce the deformation of machines during the design or construction phase of the machine tool [2] such as screw or nut cooling, using thermally insensitive materials and symmetric design. The error prevention method can control the thermal errors of machines to some extent but has some disadvantages such as higher cost. Moreover, not all the feed drive systems can be designed as a heat symmetric structure. The error prevention method compensates any changes in dimensions due to thermal fluctuations. This method can be implemented during any design/construction phase of the machine tool [3]. The error prevention method is a "soft technology" and inexpensive, but the problem is how to generate opposite errors in a machine tool rationally at a special time and position.

Many studies have developed compensation schemes to counteract the thermal deformation of a feed drive system. Some studies have established thermal error models using the multiple linear regression method [4-7]. However, the multiple linear regression method has poor robustness. If the position and speed of a feed drive system in an actual cutting process is different from those of the modeling tests, the prediction effects will be poor. Other studies have established thermal error models using the artificial neural network and other methods [8-11]. An artificial neural network can only provide a better effect when complete input and output information are used. Mistakes can occur if inaccurate input and output information are used. In summary, the current studies established thermal error models by mainly using the mathematical methods to predict thermal errors by reading the temperatures of the critical points in real time. The main disadvantage of the existing methods is that when the moving state of the machine tool is changed, the prediction effect will be poor. Moreover, many temperature sensors are needed to obtain high accuracy, resulting in a higher cost and lower system reliability.

Some machine tool builders have applied thermal error compensation on CNC machine tools such as OKUMA's thermofriendly technology and MAZAK's intelligent thermal shield. However, most of them compensate the thermal errors 


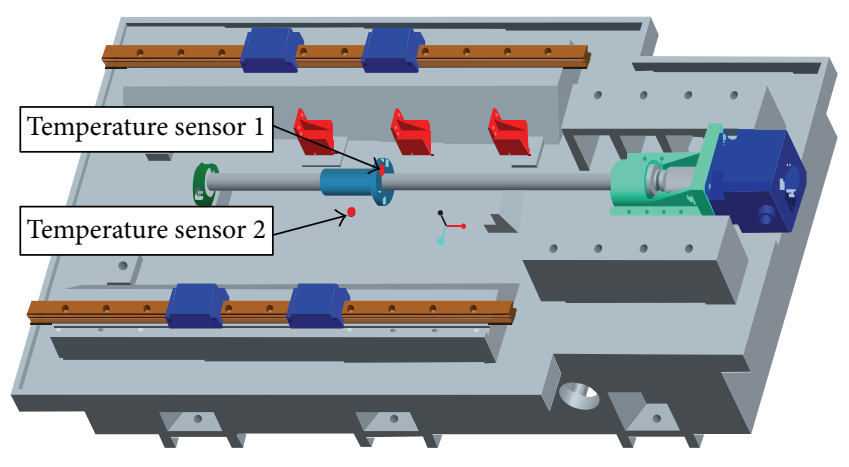

FIgURE 1: Placement of temperature sensors on the machine tool.

caused by ambient temperature variation and spindle rotation. For the thermal errors caused by ball-screw friction, ball screw or nut cooling is used instead of error compensation.

According to the current studies and applications of thermal error compensation, a new robust modeling method based on the heat transfer theory is proposed. In this modeling method, the thermal errors caused by ambient temperature variation and ball-screw friction were calculated separately. Based on the heat production, heat conduction, and heat convection theory, the ball-screw temperature field at any time can be obtained to predict ball-screw thermal errors. Finally, the developed method was compared with the multiple regression modeling method through simulation and experiment.

\section{Testing of Thermal Errors}

The thermal errors of a feed drive system were investigated on the $x$-axis of a vertical machining center. This machine tool used a cross-sliding table structure with one end fixed and one end supporting ball screws. The control system used is FANUC $0 i$ MATE-MD, the strokes of $x / y / z$-axis are $850 / 500 / 540 \mathrm{~mm}$, respectively, and the maximum speeds are $32 / 32 / 30 \mathrm{~m} / \mathrm{min}$, respectively.

Two temperature sensors, whose tolerance is $\pm 0.1^{\circ} \mathrm{C}$ (5$45^{\circ} \mathrm{C}$ ), were placed on the nut and base near the bearing block [12-14], as shown in Figure 1. Several experiments were conducted to optimize the best placement of the temperature sensors.

Thermal errors were investigated using a dual-frequency laser interferometer XL80 system, as shown in Figure 2. Importantly, the "expansion compensation" should be set at $20^{\circ} \mathrm{C}$ to cancel the ambient temperature compensation function of the software.

The tests were conducted under five moving states, and the test parameters are shown in Table 1.

For example, the procedure of thermal tests in state 1 is described as follows:

(1) Test the positioning error of $x$-axis in the range 0 $700 \mathrm{~mm}$, and record the values of temperature sensors 1 and 2.

(2) Let $x$-axis move in the range $210-490 \mathrm{~mm}$ at $8000 \mathrm{~mm} / \mathrm{min}$ for a period of time $(\sim 10 \mathrm{~min})$.
TABLE 1: Parameters of thermal error tests.

\begin{tabular}{lcc}
\hline & $\begin{array}{c}\text { Speed } \\
(\mathrm{mm} / \mathrm{min})\end{array}$ & $\begin{array}{c}\text { Range } \\
(\mathrm{mm})\end{array}$ \\
\hline State 1 & 8000 & $210-490$ \\
State 2 & 6500 & $210-490$ \\
State 3 & 15000 & $210-490$ \\
State 4 & 8000 & $0-210$ \\
State 5 & 8000 & $0-700$ \\
\hline
\end{tabular}

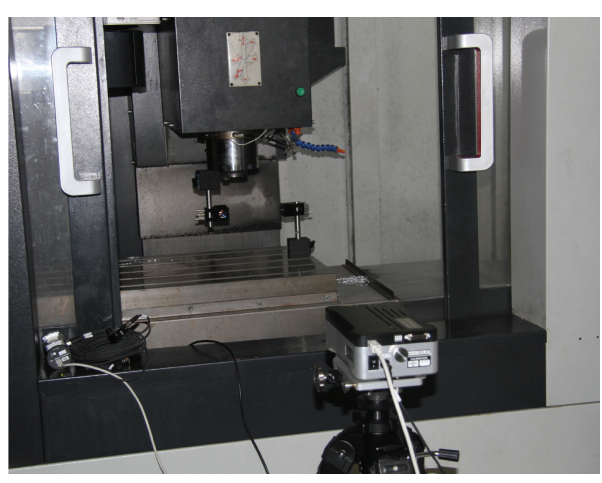

FIGURE 2: Investigation of thermal errors using a laser interferometer.

(3) Stop moving. Test the positioning error, and record the values of temperature sensors 1 and 2 .

(4) Repeat steps (2) and (3) until $x$-axis reaches the heat balance.

(5) Let $x$-axis stop at a certain position to cool down. Test the positioning error at intervals ( $\sim 10 \mathrm{~min})$, and record the values of temperature sensors 1 and 2 .

Based on the above tests, thermal error curves (Figure 3) and temperature curves (Figure 4) were obtained. In Figure 3, the warm-up curves are marked in blue, and the cool-down curves are marked in red.

Tests were conducted under states $2-5$ in the same manner.

\section{Multiple Regression Modeling Method}

The multiple regression model is a multiple-input-singleoutput system. The multiple regression method has some advantages such as a simple modeling procedure. When the moving state of a machine tool is constant, a relatively high compensation accuracy can be obtained. The thermal error model established with the multiple regression method can be described as follows:

$$
\begin{aligned}
E= & \left(a_{m} T_{n}^{m}+a_{m-1} T_{n}^{m-1}+\cdots+a_{1} T_{n}+b_{m} T_{b}^{m}\right. \\
& \left.+b_{m-1} T_{b}^{m-1}+\cdots+b_{1} T_{b}+c\right) P_{x},
\end{aligned}
$$

where $T_{n}$ is the real-time temperature of sensor $1,{ }^{\circ} \mathrm{C} ; \mathrm{T}_{b}$ is the real-time temperature of sensor $2,{ }^{\circ} \mathrm{C} ; P_{x}$ is the realtime position of $x$-axis, $\mathrm{mm} ; a_{i}$ and $b_{i}$ are the multinomial coefficient of $T_{n}$ and $T_{b}$, respectively. 


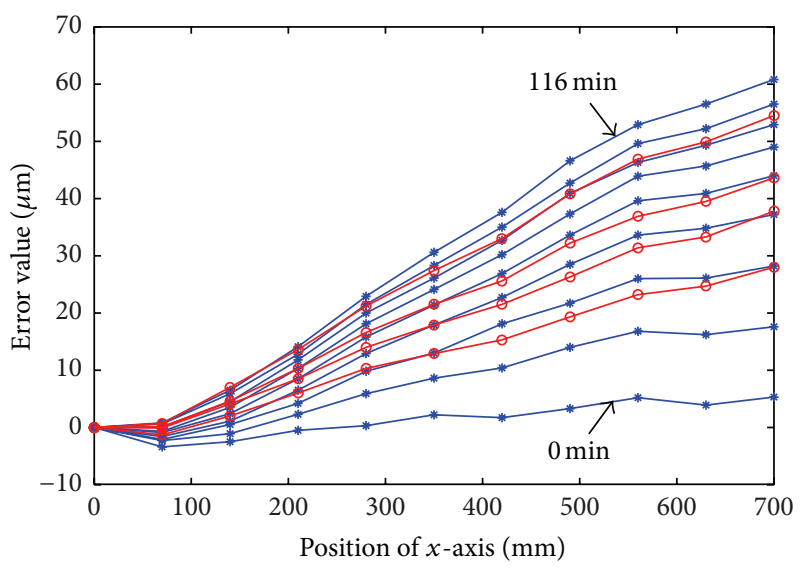

FIgURE 3: Thermal error curves of $x$-axis.

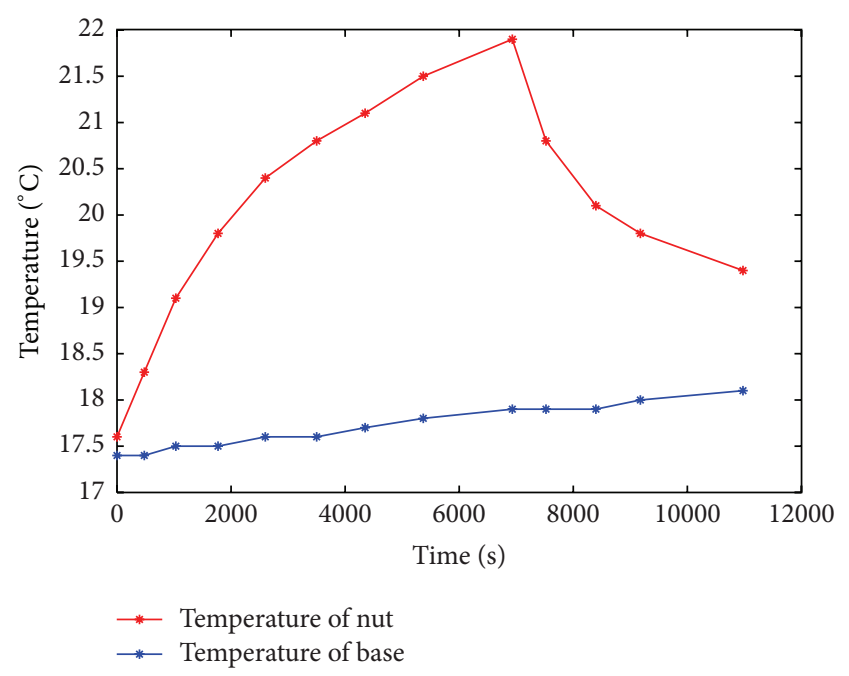

FIgURE 4: Temperature curves of $x$-axis.

$a_{i}$ and $b_{i}$ can be determined using the least square method. According to previous studies, the maximum degree of polynomial $m \leq 4$. Moreover, $\Delta T_{n}$ and $\Delta T_{b}$ can be used instead of $T_{n}$ and $T_{b}$ in (1) to obtain the same result. Because they are both used to fit the slopes of the thermal error curves, the only difference is the values of $a_{i}, b_{i}$, and $c$.

\section{Robust Modeling Method Based on the Heat Transfer Theory}

The thermal error $E$ of a feed drive system can be divided into two parts: $E_{e}$ (caused by the changes in ambient temperature) and $E_{m}$ (caused by the nut's movement). According to the temperature superposition principle, they can be superposed [15]; that is, the temperature response of multiple sources is the same as the sum of the temperature responses of all the single sources.

The screw is discretized into $M$ segments, and the length of each segment is $L$, as shown in Figure 5.

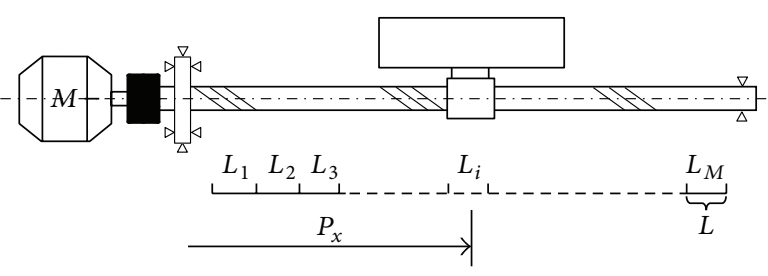

FIGURE 5: Discretization of the screw.

4.1. Errors Caused by the Changes in Ambient Temperature. In general, the change in ambient temperature is slow. Therefore, the change in ball-screw temperature caused by the change in ambient temperature is also slow. Therefore, $E_{e}$ can be described as follows:

$$
E_{e}=\alpha\left(T_{b}-T_{b 0}\right) P_{x},
$$

where $\alpha$ is the thermal expansion coefficient of ball screw, $\mu \mathrm{m} /\left(\mathrm{m} \times{ }^{\circ} \mathrm{C}\right) ; T_{b}$ is the real-time temperature of sensor $2,{ }^{\circ} \mathrm{C}$; $T_{b 0}$ is the initial temperature of sensor 2 during the test, ${ }^{\circ} \mathrm{C}$.

4.2. Errors Caused by Movement. The temperature distribution of each point in an object is known as temperature field, which is not only the function of position but also the function of time [16]. Because ball-screw axial thermal deformation is the main source of accuracy loss in a feed drive system, ball screw can be simplified to a one-dimensional bar.

For a certain segment $L_{i}$ of ball screw, nut friction can cause a temperature rise of $L_{i}$. $L_{i}$ will conduct heat to both sides of $L_{i}$ and simultaneously exchange the heat with the surrounding air. Therefore, the thermal equilibrium equation for $L_{i}$ can be expressed as follows:

$$
c m \Delta T_{L_{i}}=Q_{L_{i}-1}-Q_{L_{i}-2}-Q_{L_{i}-3},
$$

where $c$ is the heat capacity of ball screw, $\mathrm{J} /\left(\mathrm{kg} \times{ }^{\circ} \mathrm{C}\right) ; m$ is the mass of a segment of ball screw, $\mathrm{kg} ; \Delta T_{L_{i}}$ is the temperature rise of $L_{i},{ }^{\circ} \mathrm{C} ; Q_{L_{i}-1}$ is the friction heat production of $L_{i}$, J; $Q_{L_{i}-2}$ is the axial heat conduction of $L_{i}$ to both sides, J; $Q_{L_{i}-3}$ is the heat convection of $L_{i}$ with the surrounding air, J.

4.2.1. Friction Heat Production. For $L_{i}$, the total friction heat production $Q_{L_{i}-1}$ is

$$
Q_{L_{i}-1}=Q N
$$

where $Q$ is the heat production of $L_{i}$ after one friction, $\mathrm{J} ; N$ is the number of frictions of $L_{i}$.

4.2.2. Axial Heat Conduction. If the nut moves on $L_{i}$ at time $t$, then the axial heat conduction $Q_{L_{i}-2}$ during $(t, t+\Delta t)$ can be expressed as follows:

$$
Q_{L_{i}-2}=\lambda A \frac{\left(T_{L_{i}}-T_{L_{i-1}}\right)+\left(T_{L_{i}}-T_{L_{i+1}}\right)}{L} \Delta t,
$$

where $\lambda$ is the coefficient of heat conduction, $\mathrm{W} /\left(\mathrm{m} \times{ }^{\circ} \mathrm{C}\right) ; A$ is the cross-sectional area of ball screw, $\mathrm{m}^{2} ; T_{L_{i}}$ is the temperature of $L_{i}$ at a certain time, ${ }^{\circ} \mathrm{C} ; T_{L_{i-1}}$ is the temperature of 
$L_{i-1}$ at a certain time, ${ }^{\circ} \mathrm{C} ; T_{L_{i+1}}$ is the temperature of $L_{i+1}$ at a certain time, ${ }^{\circ} \mathrm{C}$.

For $L_{1}$ and $L_{M}$ especially,

$$
\begin{gathered}
Q_{L_{1}-2}=\lambda A \frac{T_{L_{1}}-T_{L_{0}}}{L_{m 0}} \Delta t+\lambda A \frac{T_{L_{1}}-T_{L_{2}}}{L} \Delta t \\
Q_{L_{M}-2}=\lambda A \frac{T_{L_{M}}-T_{L_{M-1}}}{L} \Delta t+\lambda A \frac{T_{L_{M}}-T_{L_{M+1}}}{L_{m 1}} \Delta t .
\end{gathered}
$$

4.2.3. Heat Convection. If the nut moves on $L_{i}$ at time $t$, then the heat convection $Q_{L_{i-3}-3}$ during time $(t, t+\Delta t)$ can be expressed as follows:

$$
Q_{L_{i}-3}=h S\left(T_{L_{i}}-T_{f}\right) \Delta t,
$$

where $h$ is the heat exchange coefficient [17], $\mathrm{W} /\left(\mathrm{m}^{2} \times{ }^{\circ} \mathrm{C}\right) ; S$ is the heat exchange area of $L_{i}, S=A \times L, \mathrm{~m}^{2} ; T_{f}$ is the ambient temperature, ${ }^{\circ} \mathrm{C}$.

$\Delta T_{L_{i}}$ can be obtained from (3)-(7).

The thermal change of ball screw is a dynamic process; therefore, the temperature field of the ball screw also changes dynamically. For $L_{i}, T_{L_{i}}(t+\Delta t)$ at time $t+\Delta t$ can be calculated using $T_{L_{i}}(t)$ at time $t[18]$ :

$$
T_{L_{i}}(t+\Delta t)=T_{L_{i}}(t)+\Delta T_{L_{i}} .
$$

Therefore, ball-screw thermal errors caused by movement at a certain time $t$ can be expressed as follows:

$$
E_{m}=\sum_{i=1}^{M} \alpha\left(T_{L_{i}}-T_{f}\right) L_{i}
$$

4.3. Total Errors of Feed Drive System. Combining (2) and (3), the total thermal error model of the feed drive system can be obtained as follows:

$$
E=E_{e}+E_{m}
$$

A robust modeling method based on the heat transfer theory considers the dynamic process of a feed drive system's temperature field; therefore, even if the moving state of the feed drive system changes, an excellent compensation result can still be obtained.

4.4. Identification of Parameters. In the robust model, some parameters are difficult to determine such as heat capacity $c$, coefficient of heat conduction $\lambda$, heat exchange coefficient $h$, and heat production of $L_{i}$ after one friction $Q$. A parameter identification method is needed to determine these parameters. The above mentioned parameters were optimized using the pointer automatic optimizer of the ISIGHT 5.0 software, and the optimal values of $c^{\prime}, h^{\prime}, \lambda^{\prime}$, and $Q^{\prime}$ were obtained.
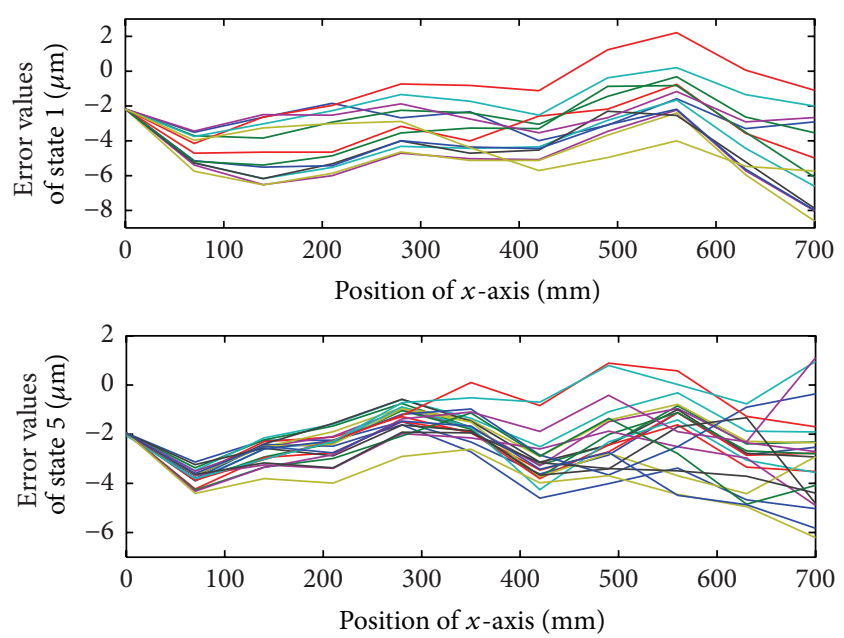

FIGURE 6: Simulation results of M1 for state 1 and M5 for state 5.

\section{Simulations and Experiments}

5.1. Simulations. The compensation results of the multiple regression model and robust model based on the heat transfer theory were compared using Matlab R2014a.

A positioning error compensation was also included in these two models considering the existing positioning errors. The positioning error compensation was used to compensate 0 min errors using the following:

$$
E_{p}=d_{4} P_{x}^{4}+d_{3} P_{x}^{3}+d_{2} P_{x}^{2}+d_{1} P_{x}+d_{0} .
$$

5.1.1. Results of the Multiple Regression Model. In a multiple regression model, $T_{n}$ 's four-order polynomial and $T_{b}$ 's oneorder polynomial were used as shown in (12), because the correlation coefficient between $T_{n}$ and $E$ is larger than that between $T_{b}$ and $E$ :

$$
E=\left(a_{4} T_{n}^{4}+a_{3} T_{n}^{3}+a_{2} T_{n}^{2}+a_{1} T_{n}+b_{1} T_{b}+c\right) P_{x} .
$$

The multiple regression models were established based on the data of states 1 and 5. M1 is the model established based on the data of state 1, and M5 is the model established based on the data of state 5 .

The compensation results of $\mathrm{M} 1$ for state 1 and $\mathrm{M} 5$ for state 5 are shown in Figure 6.

The compensation results of M1 for states 2-5 are shown in Figure 7.

5.1.2. Results of the Robust Model Based on the Heat Transfer Theory. A robust model based on the heat transfer theory was established based on the data of state 1 . The compensation results for states 1-5 are shown in Figure 8.

Figures 6-8 show that if the modeling state is the same as the verifying state, good compensation results can be obtained from the multiple regression model; otherwise the compensation results are poor. However, good compensation results can be obtained from a robust model based on the heat transfer theory even if the modeling state is not the same as 

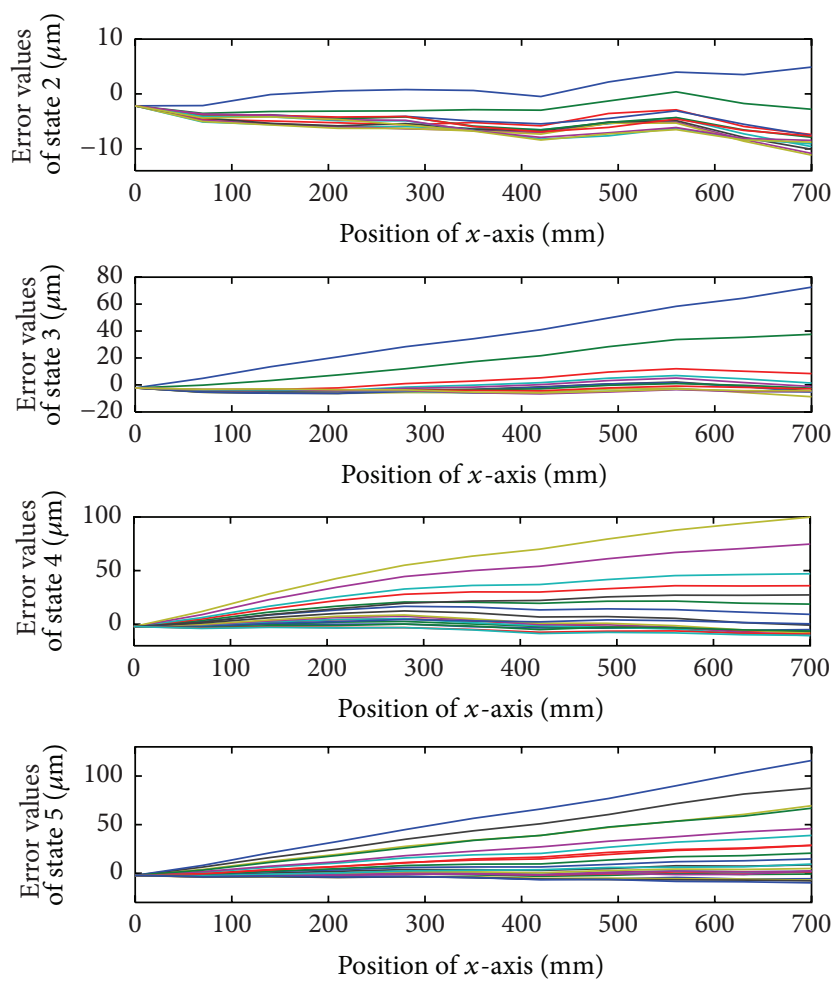

FIGURE 7: Simulation results of M1 for states 2-5.
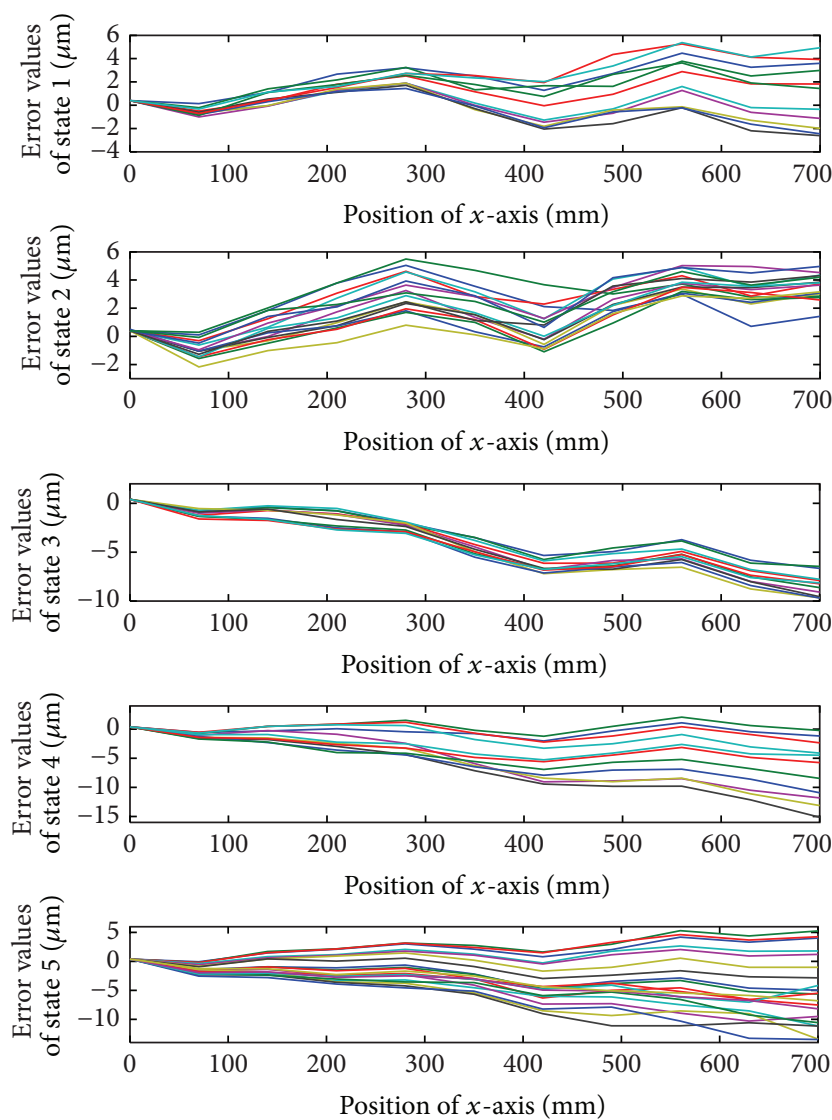

FIGURE 8: Simulation results for states 1-5.
TABLE 2: Moving states in compensation tests.

\begin{tabular}{lccc}
\hline & $\begin{array}{c}\text { Speed } \\
(\mathrm{mm} / \mathrm{min})\end{array}$ & $\begin{array}{c}\text { Range } \\
(\mathrm{mm})\end{array}$ & $\begin{array}{c}\text { Time } \\
(\mathrm{min})\end{array}$ \\
\hline State 1 & 8000 & $0-280$ & 6 \\
State 2 & 5000 & $490-700$ & 10 \\
State 3 & 10000 & $240-450$ & 5 \\
State 4 & 12000 & $0-700$ & 2 \\
\hline
\end{tabular}

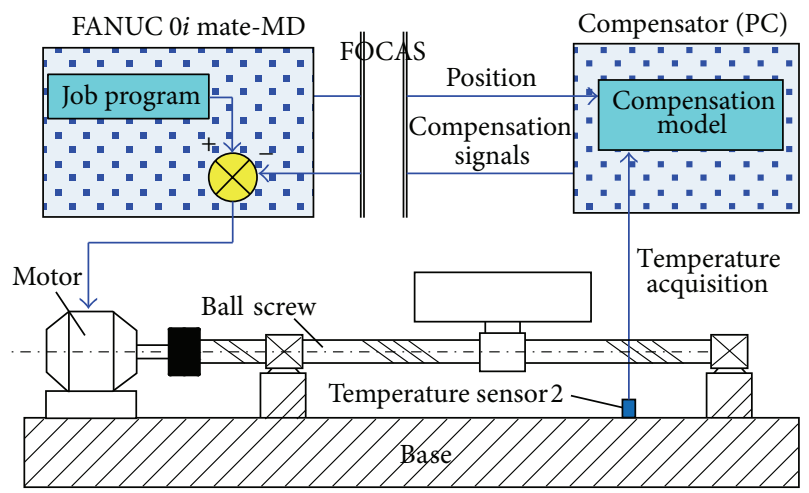

FIGURE 9: Diagram of data acquisition and error compensation.

the verifying states, because the robust model considers the moving information of a feed drive system. Therefore, it can be concluded that the robust model based on the heat transfer theory has stronger adaptability than a multiple regression model.

5.2. Experiments. The advantages of the robust model based on the heat transfer theory were verified by simulation reported in Section 5.1. In this section, the compensation effect will be verified through experiments.

The reading of a feed drive system's position from CNC and the writing of compensation values to $\mathrm{CNC}$ are needed for compensation experiments. Fanuc Open CNC API Specifications (FOCAS) was used to obtain these reading and writing functions, as shown in Figure 9.

The $x$-axis was moved according to the moving states shown in Table 2.

Position errors were investigated using a laser interferometer after each moving state, and the results are shown in Figure 10.

The simulation and test results in Figures 8 and 10 show that good compensation results were obtained from the robust model based on the heat transfer theory under different moving states.

\section{Conclusions}

The disadvantages of existing thermal error models were analyzed, and a new robust model based on the heat transfer theory was proposed. Multiple regression and robust models were derived and used for simulations and experiments. The results show that the robust model based on the heat transfer theory has better accuracy and robustness and can satisfy 


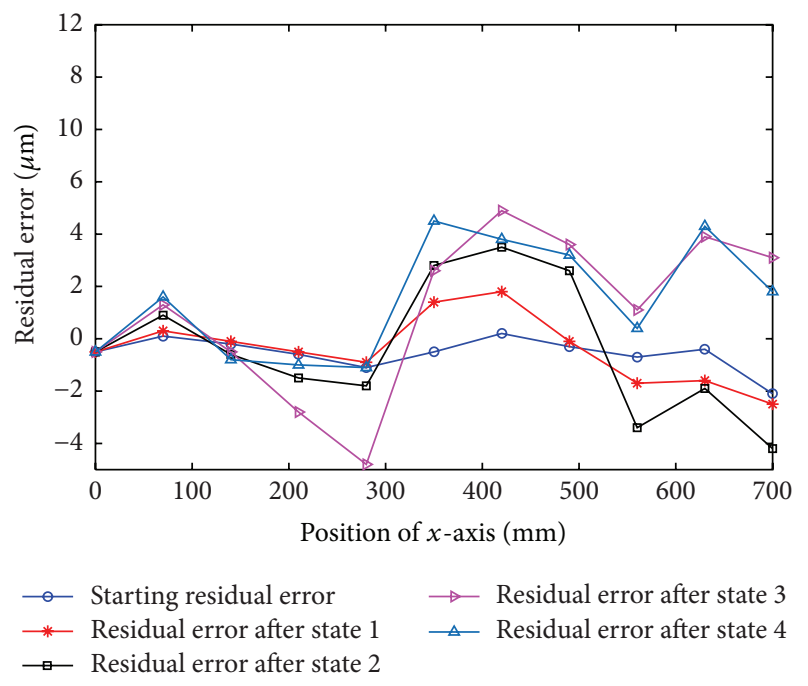

FIGURE 10: Compensation effects of the robust model based on the heat transfer theory.

the actual application. The advantages of this technology are as follows:

(1) Only one temperature sensor is needed for a linear axis in real-time compensation, and the cost is low.

(2) The manufacturing accuracy of a single workpiece can be improved.

(3) The manufacturing consistency of the bulk of workpiece can be improved, and the rejection rate can be reduced.

(4) Machines do not need to warm up before the machining. Thus, time and power costs can be saved.

(5) Machines do not depend on a constant-temperature workshop, and construction and power costs can be saved.

Through the above analyses, it can be concluded that this technology has excellent potential.

\section{Conflict of Interests}

The authors declare that there is no conflict of interests regarding the publication of this paper.

\section{Acknowledgments}

This research was supported by National Science and Technology Major Project of People's Republic of China (2013ZX04011011).

\section{References}

[1] R. Ramesh, M. A. Mannan, and A. N. Poo, "Error compensation in machine tools-a review. Part I. Geometric, cutting-force induced and fixture-dependent errors," International Journal of Machine Tools and Manufacture, vol. 40, no. 9, pp. 1235-1256, 2000.
[2] M. Mori, H. Mizuguchi, M. Fujishima, Y. Ido, N. Mingkai, and K. Konishi, "Design optimization and development of CNC lathe headstock to minimize thermal deformation," CIRP Annals-Manufacturing Technology, vol. 58, no. 1, pp. 331-334, 2009.

[3] E. Creighton, A. Honegger, A. Tulsian, and D. Mukhopadhyay, "Analysis of thermal errors in a high-speed micro-milling spindle," International Journal of Machine Tools and Manufacture, vol. 50, no. 4, pp. 386-393, 2010.

[4] J. Zhu, J. Ni, and A. J. Shih, "Robust machine tool thermal error modeling through thermal mode concept," Journal of Manufacturing Science and Engineering, vol. 130, no. 6, pp. 0610061-0610069, 2008.

[5] O. Horejs, M. Mares, P. Kohout, P. Barta, and J. Hornych, "Compensation of machine tool thermal errors based on transfer functions," MM Science Journal, pp. 162-165, 2010.

[6] M. Pajor and J. Zapłata, "Compensation of thermal deformations of the feed screw in a CNC machine tool," Advances in Manufacturing Science and Technology, vol. 35, pp. 9-17, 2011.

[7] J. Zhu, Robust thermal error modeling and compensation for CNC machine tools [Ph.D. thesis], University of Michigan, Ann Arbor, Mich, USA, 2008.

[8] C. D. Mize and J. C. Ziegert, "Neural network thermal error compensation of a machining center," Precision Engineering, vol. 24, no. 4, pp. 338-346, 2000.

[9] Z. F. Jin and P. Wang, "Neural network-based thermal error modeling in ball screw," in Modular Machine Tool and Automatic Manufacturing Technique, pp. 67-70, 2012.

[10] M. T. Ozkan, "Experimental and artificial neural network study of heat formation values of drilling and boring operations on $\mathrm{Al}$ 7075 T6 workpiece," Indian Journal of Engineering and Materials Sciences, vol. 20, no. 4, pp. 259-268, 2013.

[11] X.-H. Yao, J.-Z. Fu, and Z.-C. Chen, "Bayesian networks modeling for thermal error of numerical control machine tools," Journal of Zhejiang University: Science A, vol. 9, no. 11, pp. 15241530, 2008.

[12] J. Y. Yan and J. G. Yang, "Application of synthetic grey correlation theory on thermal point optimization for machine tool thermal error compensation," International Journal of Advanced Manufacturing Technology, vol. 43, no. 11-12, pp.1124-1132, 2009.

[13] T. Zhang, W. H. Ye, R. J. Liang, P. H. Lou, and X. L. Yang, "Temperature variable optimization for precision machine tool thermal error compensation on optimal threshold," Chinese Journal of Mechanical Engineering, vol. 26, no. 1, pp. 158-165, 2013.

[14] Y. X. Li, J. G. Yang, T. Gelvis, and Y. Y. Li, “Optimization of measuring points for machine tool thermal error based on grey system theory," International Journal of Advanced Manufacturing Technology, vol. 35, no. 7-8, pp. 745-750, 2008.

[15] J. Y. Xia, B. Wu, and Y. M. Hu, "The thermal dynamic characteristic of ball-screw under the variational multi-thermal source," Chinese Mechanical Engineering, vol. 19, pp. 955-958, 2008.

[16] B. J. Liu, Temperature field and thermal deformation of feed system on gantry machining center [Ph.D. thesis], Nanjing University of Aeronautics and Astronautics, Nanjing, China, 2013.

[17] A. Verl and S. Frey, "Correlation between feed velocity and preloading in ball screw drives," CIRP Annals-Manufacturing Technology, vol. 59, no. 1, pp. 429-432, 2010.

[18] G. Holroyd, The modeling and correction of ball-screw geometric, thermal and load errors on CNC machine tools [Ph.D. thesis], University of Huddersfield, Huddersfield, UK, 2007. 


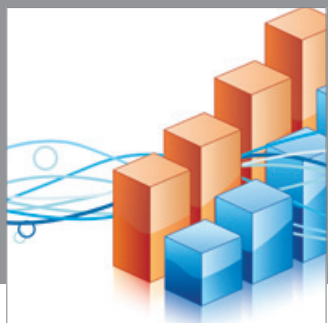

Advances in

Operations Research

mansans

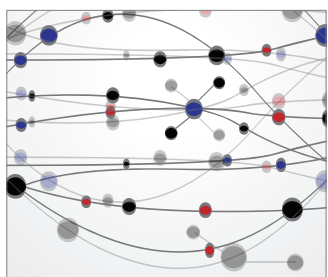

The Scientific World Journal
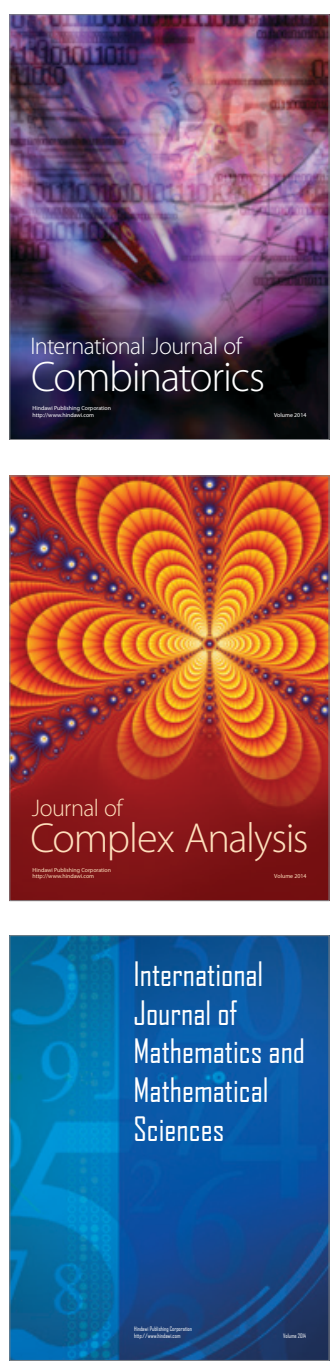
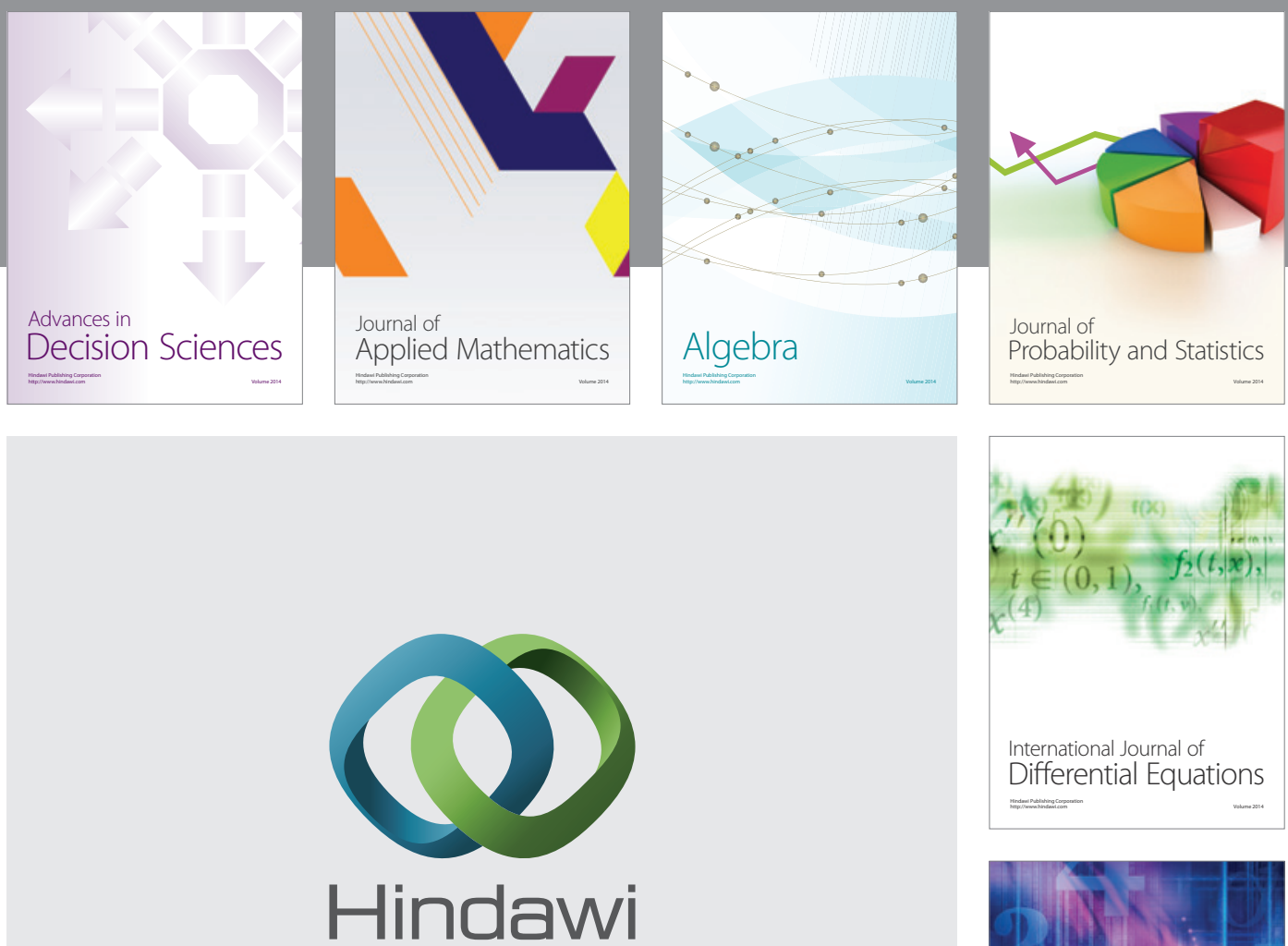

Submit your manuscripts at http://www.hindawi.com
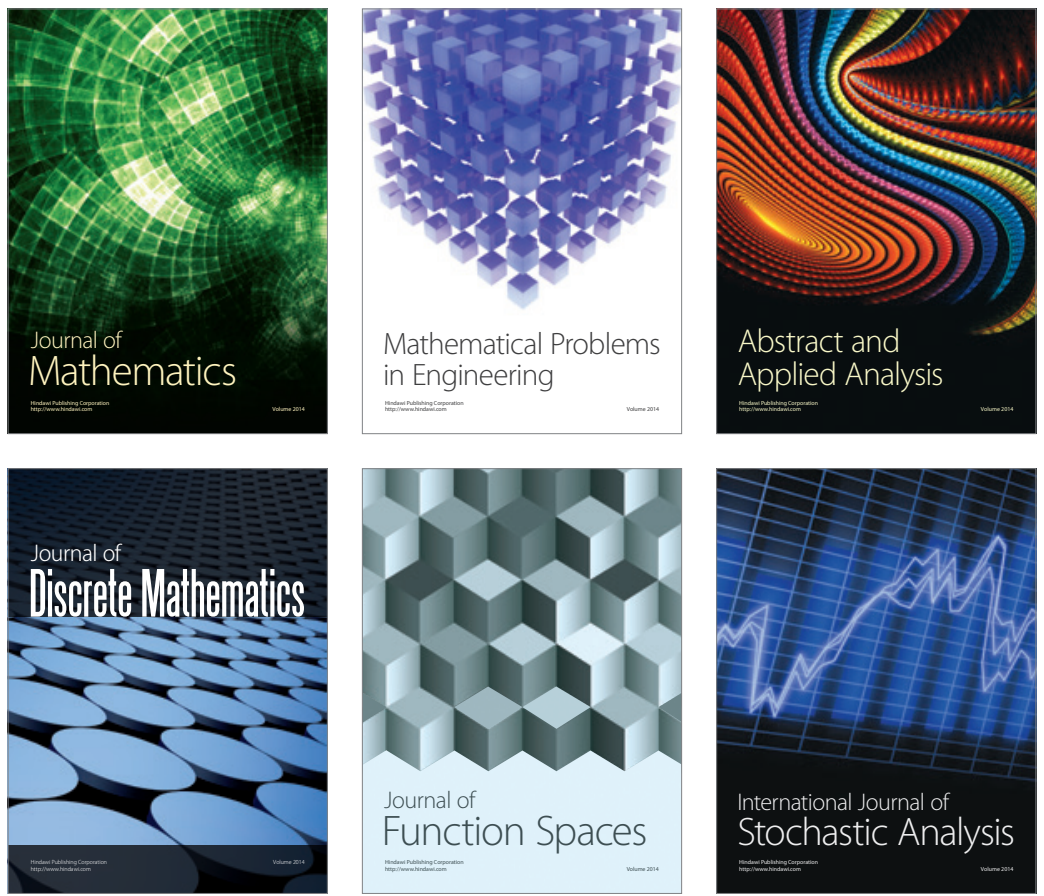

Journal of

Function Spaces

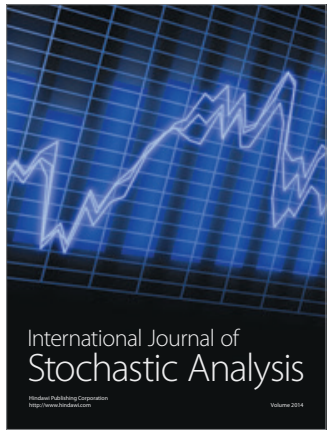

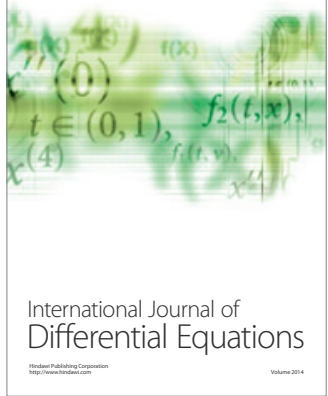
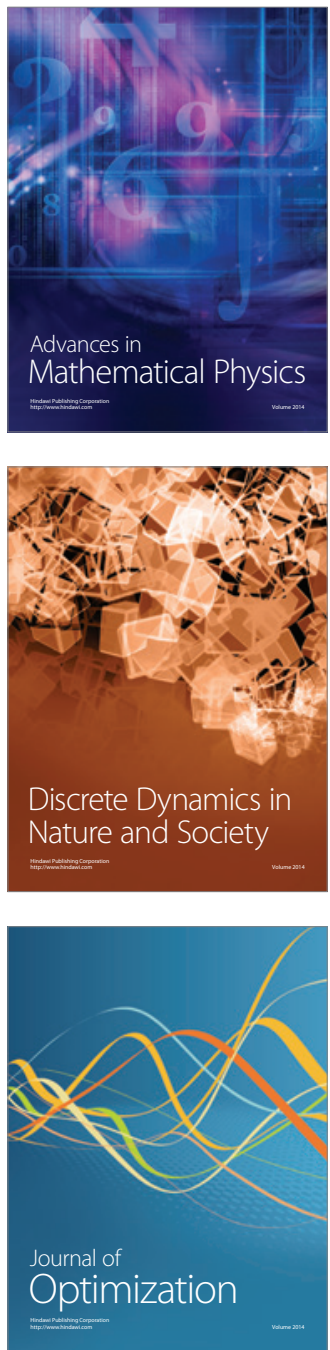